\title{
Efficacy evaluation of Veeralin $L N$, a PBO-incorporated alpha-cypermethrin long-lasting insecticidal net against Anopheles culicifacies in experimental huts in Odisha State
}

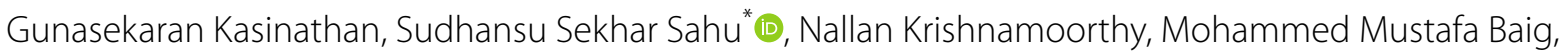 \\ Sonia Thankachy, Smrutidhara Dash, Swaminathan Subramanian and Purushothaman Jambulingam
}

\begin{abstract}
Background: The success of malaria control using long-lasting insecticidal nets (LLINs) is threatened by pyrethroid resistance developed by the malaria vectors, worldwide. To combat the resistance, synergist piperonyl butoxide (PBO) incorporated LLINs is one of the available options. In the current phase II hut trial, the efficacy of Veeralin ${ }^{\circledR} \mathrm{LN}$ (an alpha-cypermethrin and PBO-incorporated net) was evaluated against Anopheles culicifacies, a pyrethroid resistant malaria vector.

Methods: The performance of Veeralin ${ }^{\circledR} \mathrm{LN}$ was compared with MAGNet ${ }^{\circledR} \mathrm{LN}$ and untreated net in reducing the entry, induced exit, mortality and blood feeding inhibition of target vector species.

Results: The performance of Veeralin was equal to MAGNet in terms of reducing hut entry, inhibiting blood feeding and inducing exophily, and with regard to causing mortality Veeralin was better than MAGNet. When compared to untreated net, a significant reduction in hut entry and blood feeding and an increase in exophily and mortality were observed with Veeralin. In cone bioassays, unwashed Veeralin caused $>80 \%$ mortality of An. culicifacies.
\end{abstract}

Conclusions: Veeralin performed equal to (entry, exit, feeding) or better than (mortality in huts and cone bioassays) MAGNet and could be an effective tool against pyrethroid resistant malaria vectors.

Keywords: Alpha-cypermethrin, Anopheles culicifacies, Experimental huts, Piperonyl butoxide, Veeralin

\section{Background}

Controlling the malaria vectors with indoor residual spraying (IRS) of insecticides and/or long-lasting insecticidal nets (LLINs) is the major approach used for preventing malaria transmission [1]. Recent studies established that up-scaling of these tools has paved way for malaria reduction in many countries [1]. Pyrethroids are the insecticides primarily used in various formulations for mosquito control especially in LLINs [1]. Due

*Correspondence: sssahu1961@gmail.com

Indian Council of Medical Research-Vector Control Research Centre,

Medical Complex, Indira Nagar, Puducherry 605006, India to the extended use of LLINs and IRS, increased spread of vector resistance to different insecticides has been reported worldwide, which could compromise the effectiveness of these interventions [1-5], thereby limiting the use of LLINs for malaria control in many parts of the world [1]. Although, new molecules with different modes of action have been pre-qualified by the World Health Organization (WHO) for LLIN treatment, synthetic pyrethroids are the primary class of insecticide licensed for treating bed nets and other netting materials used for personal protection [6]. Therefore, there is a need for preserving the effectiveness of pyrethroid-based LLINs/ vector control tools [1]. The efficacy of LLINs could be 
sustained against malaria vectors for a minimum of three years without any re-treatment with a good LLIN technology [7-9].

Current interest of the manufacturers is to focus on developing innovative control strategies that can combat pyrethroid resistance [10, 11]. For controlling pyrethroid resistant mosquitoes, the only available alternative is piperonyl butoxide (PBO) incorporated LLINs which are having increased efficacy against pyrethroid-resistant malaria vectors $[9,12]$. Further, this is an insecticide resistance management approach and a potential means to fight against insecticide resistance [1]. The PBOLLINs were shown to be effective against some resistant populations of Anopheles in experimental hut trials [11, 13]. As there is a need to look for new products that are efficient against pyrethroid-resistance malaria vectors, PBO-incorporated pyrethroid nets have been approved with an interim recommendation $[9,14]$ pre-qualified by the WHO as a new class of vector control products [15]. Two PBO-LLINs, DawaPlus 3.0 and DawaPlus 4.0, have been granted an interim recommendation in 2017 [14], and five more PBO-LLINs, namely PermaNet 3.0, Olyset Plus, Veeralin, Tsara Boost and Tsara Plus, have been pre-qualified by the WHO in 2018 [6]. The current article summarizes the phase II evaluation of Veeralin ${ }^{\circledR} \mathrm{LN}$ conducted in a setting (an area) where the malaria vector, $A n$. culicifacies was resistant to synthetic pyrethroids [16]. The performance of the Veeralin LLIN was compared with the MAGNet LLIN, a WHO-pre-qualified alphacypermethrin LLIN [6] (positive control) and with a negative control, an untreated net. The efficacy of Veeralin was evaluated in experimental huts that simulate domestic habitations, against a free flying wild population of An. culicifacies in terms of preventing hut entry, inducing exit, inhibiting blood-feeding and causing mortality in a tribal district of Odisha State, India.

\section{Methods}

\section{Trial site and study design}

The current Phase II trial was carried out in experimental huts located at the village, Kandhaguda of Malkangiri District $\left(17^{\circ} 45^{\prime} \mathrm{N}\right.$ to $18^{\circ} 40^{\prime} \mathrm{N}$ and $81^{\circ} 10^{\prime} \mathrm{E}$ to $\left.82^{\circ} 00^{\prime} \mathrm{E}\right)$ in Odisha State. The major human malaria parasite species prevailing in this area was Plasmodium falciparum. Transmission of malaria peaks in the district during rainy (July-August) and cooler months (November-December). The two vector species that transmit malaria in this area were Anopheles fluviatilis and An. culicifacies. Anopheles fluviatilis was highly susceptible to synthetic pyrethroids whereas, An. culicifacies was found to be resistant [16] with moderate resistance intensity/level [17]. The specifications of the hut construction have been described elsewhere [18].

\section{Description of the test product}

In the test LLIN, Veeralin ${ }^{\circledR} \mathrm{LN}$, manufactured by VKA Polymers, Tamil Nadu, India, the pyrethroid insecticide, alpha-cypermethrin was integrated into monofilament polyethylene fibres of 130 denier at a target dose of $6.0 \mathrm{~g}$ $\mathrm{AI} / \mathrm{kg}$, equivalent to $216 \mathrm{mg} \mathrm{AI} / \mathrm{m}^{2}$ of insecticide, and $2.2 \mathrm{~g} / \mathrm{kg}$ of $\mathrm{PBO}$, equivalent to $79.2 \mathrm{mg} / \mathrm{m}^{2}$. In the current trial, six arms viz., Veeralin unwashed and washed 20 times, MAGNet unwashed and 20 times washed (positive control), untreated net (negative control) and 25 times washed Veeralin ${ }^{\circledR} \mathrm{LN}$ were compared. All the trial nets (size $180 \times 160 \times 150 \mathrm{cms}$ ) were sponsored by VKA Polymers. Each arm had six replicate nets and every night different replicate nets of the same arm were tested in each hut for each week. Chemical analysis and cone bioassays before any wash and after 20 or 25 washes were carried out on additional nets.

\section{Washing and cone-bioassays}

Nets were washed according to the $\mathrm{WHO}$ washing protocol [8]. Cone bioassays were performed on the net surfaces of the additional nets included for this purpose in each treatment arm. Before any wash and after 20 or 25 washes, for the cone bioassays, laboratory-reared, pyrethroid susceptible Anopheles stephensi mosquitoes were used as An. culicifacies, the target test mosquito species was not available at the rearing facility of Indian Council of Medical Research (ICMR)-Vector Control Research Centre (VCRC), Puducherry, where washing of nets was carried out. Bioassays were also carried out at the field site i.e., after the evaluation in the experimental huts, exposing wild caught pyrethroid resistant An. culicifacies and pyrethroid susceptible Anopheles jeyporiensis on one net selected randomly from the six replicate nets of each arm used in the experimental huts. On each net, bioassays were performed on all the five panels (one roof and four side panels). Two cone tests were carried out on each panel, releasing five mosquitoes per cone test. Thus, a total of 50 mosquitoes each of the susceptible and resistant species were tested per net. The mosquitoes were exposed for $3 \mathrm{~min}$ and after the exposure, they were held for $24 \mathrm{~h}$ at temperature $27 \pm 2{ }^{\circ} \mathrm{C}$ and humidity $75 \pm 10 \%$. During the holding time, the mosquitoes were provided with sugar solution for feeding. The mortality was recorded after $24 \mathrm{~h}$.

\section{Analysis for insecticide content in nets}

To determine the alpha-cypermethrin and PBO content in the treatment arms, chemical analysis of LLIN samples was done, prior to and after washing 20 or 25 times and after hut evaluation. Prior to wash, 5 pieces, one $(30 \times 30 \mathrm{~cm})$ from each of the 5 positions, were cut 
and removed from one of the three additional nets of each arm. For chemical analysis, net samples were also obtained from 20 times washed (2nd additional net) and 25 times washed net (3rd additional net), and similarly from unwashed arms. After experimental hut study, from each arm, one of the six replicate nets used in the huts was randomly chosen for the analysis. The samples, after packing in aluminium foil, were labelled and stored at $+4{ }^{\circ} \mathrm{C}$ and sent to the WHO Collaborating Centre, Gembloux, Belgium, for analysing the active ingredient content of alpha-cypermethrin and PBO.

\section{Selection of volunteers for hut evaluation}

For sleeping in experimental huts, 12 adult volunteers, two (preferably husband and wife) for each hut, were selected from the village through organizing a meeting. To engage human participants in the hut evaluation, clearance was obtained from the ICMR-VCRC Human Ethics Committee. Prior written consent was obtained from the volunteers for their participation. The volunteers were told to sleep under the net using the bed materials that were allotted to them from 19.00 to $05.30 \mathrm{~h}$ with a small interval for dinner and not to make any fire or smoke inside the hut.

\section{Net preparation and rotation of nets and volunteers in experimental huts}

Before starting the evaluation, in each of the six replicate nets of all the arms, a total of six holes (each one: $4 \mathrm{~cm} \times 4 \mathrm{~cm}$ ) were made to give an effect of a torn net. Six teams, each with two sleepers, were formed. The nets and the sleepers were rotated as per the Latin square design to reduce the differences due to attractiveness of huts and volunteers. One treatment arm was tested for one week in each hut with one replicate net each day. The sleepers were rotated among the huts daily, whereas, the arms were rotated weekly. The collection and processing of mosquitoes have been described elsewhere [18].

\section{Data collection and analysis}

The number of mosquitoes entered, exited, dead inside the hut and the number that succeeded to feed on volunteers were calculated for each arm by compiling the data collected over 12 weeks. The day-wise entry of An. culicifacies in each arm was recorded. As the variance was higher than the mean; negative binomial regression analysis (using Stata software, Version 14) was done by taking the number collected as dependent variable and the experimental arms as independent variable. The number of An. culicifacies exited, blood fed and dead after $24 \mathrm{~h}$ (total mortality) day-wise and arm-wise were analysed using logistic regression (using SPSS 16.0) by taking mosquitoes exited, fed and dead (total mortality) as dependent variables and arms as categorical covariates. For overall comparison, the negative control (untreated net) was kept as reference category. Further comparisons between the treated arms were made by removing negative control from the grouped data and holding the positive control (unwashed MAGNet) as reference category. The mean alpha-cypermethrin and PBO content in the net samples prior to any wash, after washing and after hut evaluation were compared using one-way ANOVA followed by a rank (LSD) test.

\section{Results}

Species composition in the experimental huts

In total, 72 collections, completing two rotations (six weeks to complete one rotation) across all treatments, were done for each of the six arms in the experimental huts. A total of 650 mosquitoes were collected. Among them, An. culicifacies formed 69.4\%, An. fluviatilis 2.3\%, and Anopheles subpictus and Anopheles vagus (non-vectors) together formed $19.5 \%$, and $8.8 \%$ was culicines. As the trial was carried out at the end of the rainy season, the number of An. fluviatilis collected was very small. Therefore, further analysis was restricted to An. culicifacies, which was resistant to alpha-cypermethrin.

\section{Entry of Anopheles culicifacies into the huts}

The mean number $\pm \mathrm{SE}$ of $A n$. culicifacies that entered the huts (entry) with unwashed Veeralin, 20 times washed Veeralin, unwashed MAGNet, 20 times washed MAGNet, untreated nets and Veeralin washed 25 times was $0.47 \pm 0.11, \quad 0.56 \pm 0.08, \quad 0.51 \pm 0.10, \quad 0.46 \pm 0.08$, $3.61 \pm 0.28$, and $0.65 \pm 0.11$, respectively from 72 collections during 12 weeks (Table 1). Out of 72 attempts of mosquito collections, on six occasions, there was no entry of An. culicifacies into the huts with untreated net, whereas, in the five treated arms; MAGNet without any wash, MAGNet after 20 washes, Veeralin without any wash, Veeralin after 20 and 25 washes, zero entry was recorded on 47, 47, 52, 40 and 43 occasions, respectively. The hut entry was significantly lower in the five treated arms $(\mathrm{p}<0.05)$ than the untreated one. It was noted from the incidence rate ratio (IRR) that, among the treated arms, the hut entry was the minimum with MAGNet washed 20 times followed by unwashed Veeralin. However, no significant difference was seen in the entry between the five treated arms indicating a similar deterrent effect of all the treated arms (Table 1).

\section{Exit from the huts}

The five treated arms induced significantly a higher exophily $(\mathrm{p}<0.05)$ than the untreated arm. The exit rate of An. culicifacies was higher with Veeralin washed 20 times $(57.5 \%)$ followed by unwashed Veeralin (52.9\%). 
Table 1 Insecticidal efficacy of different arms on entry, exit, mortality and blood-feeding of An. culicifacies collected in the experimental hut trials

\begin{tabular}{|c|c|c|c|c|c|c|}
\hline & $\begin{array}{l}\text { Unwashed Veeralin } \\
\text { LN }\end{array}$ & $\begin{array}{l}\text { Veeralin LN } \\
\text { washed } 20 \text { times }\end{array}$ & $\begin{array}{l}\text { Unwashed } \\
\text { MAGNet LN }\end{array}$ & $\begin{array}{l}\text { MAGNet LN } \\
\text { washed } 20 \text { times }\end{array}$ & $\begin{array}{l}\text { Untreated } \\
\text { polyester } \\
\text { net }\end{array}$ & $\begin{array}{l}\text { Veeralin LN washed } \\
25 \text { times }\end{array}$ \\
\hline $\begin{array}{l}\text { Number of collec- } \\
\text { tions }\end{array}$ & 72 & 72 & 72 & 72 & 72 & 72 \\
\hline $\begin{array}{l}\text { Total females } \\
\text { entered }\end{array}$ & 34 & 40 & 37 & 33 & 260 & 47 \\
\hline IRR (95\% CI) & $0.130(0.088-0.193)$ & $0.153(0.106-0.222)$ & $0.142(0.097-0.207)$ & $0.126(0.085-0.188)$ & $1.00^{\mathrm{a}}$ & $0.180(0.127-0.256)$ \\
\hline$p$ & 0.000 & 0.000 & 0.000 & 0.000 & - & 0.000 \\
\hline $\begin{array}{l}\text { Total females exit in } \\
\text { veranda trap (Exit } \\
\text { rate in \%) }\end{array}$ & $18(52.9)$ & $23(57.5)$ & $15(40.5)$ & $17(51.5)$ & $65(25.0)$ & $24(51.1)$ \\
\hline Odds ratio $(95 \% \mathrm{Cl})$ & $3.375(1.627-7.001)$ & $4.059(2.042-8.067)$ & $2.045(1.002-4.176)$ & $3.187(1.524-6.668)$ & $1.00^{\mathrm{a}}$ & $3.130(1.655-5.920)$ \\
\hline $\mathrm{p}$ & 0.001 & 0.000 & 0.049 & 0.002 & - & 0.000 \\
\hline $\begin{array}{l}\text { Total females blood } \\
\text { fed ( } \% \text { blood } \\
\text { feeding) }\end{array}$ & $23(67.6)$ & $22(55.0)$ & $21(56.8)$ & $19(57.6)$ & $246(94.6)$ & $29(61.7)$ \\
\hline $\begin{array}{l}\text { \% Blood feeding } \\
\text { inhibition }\end{array}$ & 28.5 & 41.9 & 40.0 & 39.1 & - & 34.8 \\
\hline Odds ratio $(95 \%$ Cl) & $0.128(0.053-0.311)$ & $0.075(0.033-0.169)$ & $0.080(0.035-0.185)$ & $0.083(0.035-0.197)$ & $1.00^{\mathrm{a}}$ & $0.083(0.038-0.180)$ \\
\hline$p$ & 0.000 & 0.000 & 0.000 & 0.000 & - & 0.000 \\
\hline $\begin{array}{l}\text { \% Personal protec- } \\
\text { tion }\end{array}$ & 90.7 & 91.1 & 91.5 & 92.3 & 0.0 & 88.2 \\
\hline $\begin{array}{l}\text { Total females dead } \\
\text { (\% total mortality) }\end{array}$ & $32(94.1)$ & $32(80.0)$ & $25(67.6)$ & $22(66.7)$ & $0(0.0)$ & $26(55.3)$ \\
\hline Odds ratio $(95 \% \mathrm{Cl})$ & $0.130(0.027-0.636)$ & $0.521(0.185-1.468)$ & $1.00^{\mathrm{a}}$ & $1.042(0.384-2.828)$ & & $1.683(0.686-4.126)$ \\
\hline$p$ & 0.012 & 0.217 & - & 0.936 & & 0.255 \\
\hline$\%$ Mass killing effect & 12.3 & 12.3 & 9.6 & 8.5 & 0.0 & 10.0 \\
\hline
\end{tabular}

a Reference category

However, the 95\% CI for the odds ratios showed no significant difference in the exit rate between the treated arms (Table 1). By taking the positive control (unwashed MAGNet) as reference category (by excluding the negative control), no significant difference was observed in exit rates of An. culicifacies among the five treated arms (logistic regression: likelihood ratio based $x^{2}=2.358$, $\mathrm{df}=4, \mathrm{p}=0.67$ ).

\section{Inhibition of blood feeding and personal protection}

The lowest blood feeding (i.e. the highest feeding inhibition) was observed with Veeralin washed 20 times (55.0\%) followed by unwashed MAGNet (56.8\%) (Table1). Overall, the feeding rate among the six experiment arms greatly differed $\left(\mathrm{x}^{2}=89.435, \mathrm{df}=5, \mathrm{p}<0.05\right)$. Compared to untreated arm, all treated arms recorded a significantly reduced feeding rate. Between the treatment arms, no significant difference was found, as shown by $95 \%$ CI for the Odds ratios. Personal protection determines the level of protection offered by each treatment arm. Among the five treatment arms, the personal protective effect was the maximum with MAGNet washed 20 times
(92.3\%) followed by unwashed MAGNet (91.5\%), Veeralin washed 20 times (91.1\%), unwashed Veeralin (90.7\%) and Veeralin washed 25 times (88.2\%).

\section{Mortality and mass killing effect}

Higher mortality was seen in all treatment arms (no mortality with untreated net), the maximum being with unwashed Veeralin (94.1\%) (Table1). Overall, the mortality differed significantly among the five treatment arms $\left(\chi^{2}=18.979, \mathrm{df}=4, \mathrm{p}=0.001\right)$ (Table 1$)$. Veeralin washed 20 and 25 times and MAGNet washed 20 times did not differ significantly from unwashed MAGNet, the positive control, in terms of causing mortality $(p>0.05)$ except unwashed Veeralin that caused a significantly greater mortality $(\mathrm{p}=0.012)$. Overall, the mass killing effect varied from 8.5\% (MAGNet washed 20 times) to 12.3 (both unwashed and 20 times washed Veeralin) (Table 1).

\section{Cone bioassay tests}

Before any wash, after 20 or 25 washes, while the treatment arms produced $100 \%$ mortality of the pyrethroid susceptible An. stephensi, the untreated nets caused zero 


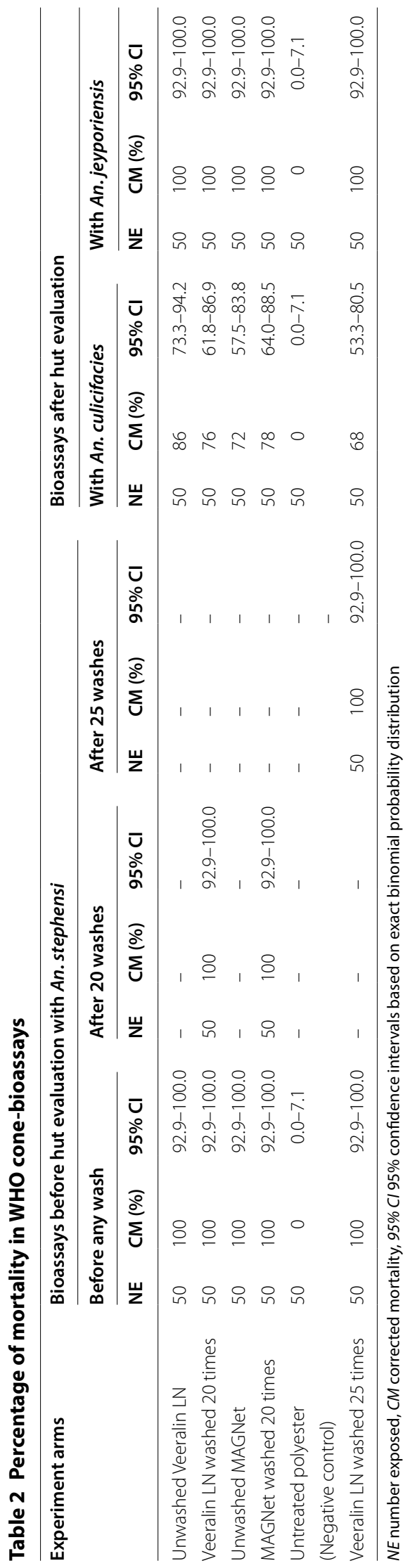


mortality. After hut evaluation, only unwashed Veeralin caused $>80 \%$ mortality of An. culicifacies, and the mortality with the other treated arms was $<80 \%$ (Table 2). The bio-assays conducted with pyrethroid susceptible $A n$. jeyporiensis on the treated arms after hut evaluation showed $100 \%$ mortality.

\section{Chemical analysis}

The average base-line (wash 0) content of alpha-cypermethrin in the net samples of the three Veeralin arms viz., unwashed Veeralin, Veeralin washed 20 times and 25 times was $5.61 \pm 0.12$ (SD), $5.61 \pm 0.08$ and $5.63 \pm 0.06 \mathrm{~g} /$ $\mathrm{kg}$, and the nets complied with the target dose of $6.0 \mathrm{~g} /$ $\mathrm{kg} \pm 25 \%(4.5 \mathrm{~g} / \mathrm{kg}-7.5 \mathrm{~g} / \mathrm{kg})$. The alpha-cypermethrin content after 20 and 25 washes was $5.44 \pm 0.07 \mathrm{~g} / \mathrm{kg}$ and $5.49 \pm 0.11 \mathrm{~g} / \mathrm{kg}$, corresponding to an overall alphacypermethrin retention of $97 \%$ and $98 \%$, respectively. After hut evaluation, the alpha-cypermethrin content was $5.59 \pm 0.06,5.52 \pm 0.05$ and $5.44 \pm 0.12 \mathrm{~g} / \mathrm{kg}$ in Veeralin unwashed and washed 20 times and 25 times, respectively. After washing (20 or 25 times), there was a decline in alpha-cypermethrin content $(\mathrm{p}<0.05$ by One-way ANOVA) compared to the base-line concentration, but, within the specifications of $\pm 25 \%$. No further diminishing of active ingredient content was observed after the hut trial $(\mathrm{p}>0.05)$.

In the two MAGNet arms, unwashed and 20 times washed, the initial alpha-cypermethrin content was $5.82 \pm 0.05$ and $5.80 \pm 0.05 \mathrm{~g} / \mathrm{kg}$ and that met comply with the target dose of $5.8 \mathrm{~g} / \mathrm{kg} \pm 25 \%(4.4-7.3 \mathrm{~g} /$ $\mathrm{kg})$. Compared to the initial level, the active ingredient concentration reduced to $5.46 \pm \mathrm{g} / \mathrm{kg}$ after 20 washes $(\mathrm{p}<0.05)$, but within the accepted margin of $\pm 25 \%$. The corresponding active ingredient retention was $94 \%$. After the hut evaluation, alpha-cypermethrin content did not decrease significantly $(\mathrm{p}>0.05)$, as it was $5.59 \pm 0.08$ for MAGNet unwashed and $5.36 \pm 0.13 \mathrm{~g} / \mathrm{kg}$ for MAGNet washed 20 times.

The mean base-line PBO content in the three Veeralin arms $(2.47 \pm 0.02,2.45 \pm 0.03$ and $2.42 \pm 0.05 \mathrm{~g} / \mathrm{kg}$, respectively) were within the acceptable range of the target dose of $2.2 \mathrm{~g} / \mathrm{kg} \pm 25 \%(1.7-2.8 \mathrm{~g} / \mathrm{kg})$. After 20 and 25 washes, there was a decrease in PBO content to $2.01 \pm 0.02 \mathrm{~g} / \mathrm{kg}$ and $2.01 \pm 0.06 \mathrm{~g} / \mathrm{kg}(\mathrm{p}<0.05$ by one-way ANOVA); however, the content was within the specification of $\pm 25 \%$. The overall retention of PBO content after washing was $82 \%$ and $83 \%$, respectively. After hut trial, while no further decline in PBO content $(2.02 \pm 0.03 \mathrm{~g} /$ $\mathrm{kg})$ was noticed in Veeralin washed 20 times $(\mathrm{p}>0.05)$, there was a decrease in 25 times washed Veeralin $(1.94 \pm 0.04 \mathrm{~g} / \mathrm{kg})(\mathrm{p}<0.05)$. In unwashed Veeralin, after hut trial, $\mathrm{PBO}$ content declined to $2.31 \pm 0.03 \mathrm{~g} / \mathrm{kg}$ compared to the base-line $(\mathrm{p}<0.05)$. However, in all cases, the
PBO content was within the acceptable range of $\pm 25 \%$ $(1.7-2.8 \mathrm{~g} / \mathrm{kg})$.

\section{Discussion}

The current study assessed the response of An. culicifacies to alpha-cypermethrin $+\mathrm{PBO}$ nets in comparison to only alpha-cypermethrin nets in reducing the entry and blood-feeding and in inducing exophily and mortality in experimental huts. There was no entry of An. culicifacies into the huts on many occasions when the volunteers slept under the treated nets (of the five treatment arms), signifying a higher deterrent effect of the pyrethroid insecticide, alpha-cypermethrin used in the treated nets. In spite of the holes made, the deterrent effect was also realized from the 10 alive An. culicifacies collected inside the untreated nets whereas, only one alive and one dead were found under the nets of the five treated arms. Thus, all the treated arms significantly reduced the entry of $A n$. culicifacies in to the huts compared to the untreated arm. Further, the washed treatment arms did not differ significantly from the unwashed with regard to hut entry indicating no impact of washing of Veeralin LN/MAGNet LN on their deterrent effect.

Considerable exit of An. culicifacies (25\%) was also noticed from the huts with untreated net (negative control), which might be due to its innate behaviour. An experimental hut study conducted recently in the same area showed that the exit rate (induced exophily) of $A n$. culicifacies in the untreated arm was $23.9 \%$ [19]. However, a higher exophily (40.5-57.5\%) was recorded with the treated arms, but between them, there was no significant difference. Veeralin without any wash and after 25 washes induced a comparable exophily, indicating the retention of insecticide even after 25 washes.

Among the treated arms, Veeralin washed 20 times (41.9\%) effected the maximum inhibition of blood feeding followed by MAGNet unwashed (40.0\%). The feeding rate was significantly lower in all the treatment arms than the untreated arm. When compared to the positive control, the blood feeding inhibition in the treatment arms did not differ significantly.

The total mortality of An. culicifacies in the five treated arms varied from 55.3 to $94.1 \%$, the maximum was by unwashed Veeralin and that was much higher than the mortality caused by the positive control. Further, the cone-bioassay results showed that only unwashed Veeralin caused $>80 \%$ mortality of An. culicifacies (pyrethroid resistant) at the end of hut evaluation. However, the enhanced mortality produced by alpha-cypermethrin + PBO LLINs was not sustained after 20 washes. Similar results were obtained in experimental hut trials in Benin, Burkina Faso and Cameroon, where deltamethrinPBO LLINs produced significantly a higher mortality of 
An. gambiae sensu lato (s.l.) (pyrethroid resistant) compared to non-PBOLLINs, with higher mortality observed with unwashed LLINs $[10,13]$.

The cone-bioassays conducted during the current trial with pyrethroid resistant An. culicifacies after hut evaluation showed that unwashed Veeralin met the efficacy criteria of $>80 \%$ mortality [8]. After washing, both Veeralin and positive control net (MAGNet) showed $<80 \%$ mortality. It was reported that the PBO content in one product with WHOPES interim recommendation remained stable after 10 laboratory washes, indicating that no PBO was being released after 10 washes and, therefore, was not bio-available on the net surface [20]. When pyrethroid susceptible mosquitoes (An. stephensi and An. jeyporiensis) were exposed to all the five treatment arms, $100 \%$ mortality was observed. It is known that against susceptible mosquito populations, pyrethroid-PBO nets may not have any effect [21], but combination or mixture LLINs with $\mathrm{PBO}$ could be effective against resistant mosquitoes whose resistance is based on oxidative metabolism [11]. Overall, the performance of unwashed Veeralin was significantly higher than the negative control (untreated net) and better than the positive control (MAGNet) in causing mortality of An. culicifacies in experimental huts. The chemical analysis though, indicated a loss of insecticide and PBO after 20 or 25 washes, their content, even after the loss, remained within the accepted range of $\pm 25 \%$. Therefore, the marked increase in mortality noticed with Veeralin LN was probably due to the addition of the synergist, $\mathrm{PBO}$, which is known to inhibit the activity of the enzymes that are responsible detoxification of pyrethroids [22]. Nevertheless, it was not possible to attain a complete control of the pyrethroid resistant An. culicifacies with Veeralin in experimental huts and this could be due to the presence of different resistance mechanisms that are not affected by the synergist, PBO [23].

Phase II LLIN evaluations mainly focus on two entomological parameters, blood feeding inhibition and mortality, which are crucial for obtaining interim recommendation/pre-qualification [24]. In the current study, Veeralin after 20 or 25 washes produced similar effect on the entomological parameters compared to the other treated arms, except mortality where unwashed Veeralin caused a higher mortality than washed ones. This clearly showed that Veeralin was comparable with/better than MAGNet.

Experimental hut studies conducted in West and Central Africa, Tanzania and Togo with high pyrethroid resistance showed that pyrethroid-PBO nets performed better than standard-LLINs [9, 10, 25], whereas in moderate to low pyrethroid resistant areas, there was little or no difference in the effect of unwashed/washed pyrethroid-PBO nets compared to unwashed/washed standard-LLINs [19, 25].
This may be due to the wide variation in insecticide resistance levels in malaria vector species. However, in the current experimental hut trial, the performance of Veeralin LN was comparable to MAGNet LN (positive control) in causing deterrence, inducing exophily and inhibiting blood feeding and better in terms of causing mortality of the pyrethroid resistant An. culicifacies.

\section{Conclusions}

In the current study, Veeralin LN performed equal to (entry, exit, feeding) or better than (mortality in huts) the reference LN (MAGNet) and fulfilled the WHO-PQ criteria of Phase II evaluation of LLINs. In view of increasing development of pyrethroid resistance in malaria vectors, PBO incorporated Veeralin LN could be an option to be considered for malaria control after fully qualified as a vector control product by the WHO.

\section{Abbreviations \\ LLIN: Long-lasting insecticidal net; PBO: Piperonyl butoxide; IRS: Indoor residual spraying; WHO: World Health Organization; WHOPES: World Health Organization Pesticide Evaluation Scheme; ICMR-VCRC: Indian Council of Medical Research-Vector Control Research Centre; SE: Standard error; IRR: Incidence rate ratio; $\mathrm{Cl}$ : Confidence intervals; df: Degrees of freedom.}

\section{Acknowledgements}

The authors are thankful to the technical staff of VCRC Field Station, Koraput for their assistance in carrying out the study. We thank VKA Polymers, India for providing the LLINs for evaluation and for the financial support for this study.

\section{Authors' contributions}

KG, SSS and PJ designed the study. SSS, TS, SD and MMB performed the study. SS compiled and analysed the data. KG and SSS drafted the manuscript. PJ critically reviewed the manuscript. All authors contributed to the writing of the manuscript and approved the final manuscript.

Funding

This research project was supported by VKA Polymers, India. The funders had no role in study design, data collection and analysis, decision to publish, or preparation of the manuscript.

\section{Availability of data and materials}

The data sets generated and/or analysed during the current study are available from the corresponding author on reasonable request.

\section{Ethics approval and consent to participate}

Ethics approval was obtained from the institutional human ethical committee of ICMR-VCRC Puducherry, India for engaging human volunteers in this study.

\section{Consent for publication}

Not applicable.

\section{Competing interests}

The authors declare that they have no competing interests.

Received: 20 April 2020 Accepted: 4 November 2020

Published online: 10 November 2020

\section{References}

1. Pryce J, Richardson M, Lengeler C. Insecticide-treated nets for preventing malaria. Cochrane Database Syst Rev. 2018;11:CD000363. 
2. N'Guessan R, Corbel V, Akogbéto M, Rowland M. Reduced efficacy of insecticide-treated nets and indoor residual spraying for malaria control in pyrethroid resistance area. Benin Emerg Infect Dis. 2007;13:199-206.

3. Sharp BL, Ridl FC, Govender D, Kuklinski J, Kleinschmidt I. Malaria vector control by indoor residual insecticide spraying on the tropical island of Bioko. Equat Guinea Malar J. 2007;6:52.

4. Czeher C, Labbo R, Arzika I, Duchemin JB. Evidence of increasing Leu-Phe knockdown resistance mutation in Anopheles gambiae from Niger following a nationwide long-lasting insecticide-treated nets implementation. Malar J. 2008;7:189.

5. WHO. Report of the eleventh WHOPES Working Group Meeting, 10-13, December 2007, Review of: Spinosad 7.48\% DT, Netprotect ${ }^{\text {(B) }}$ Duranet ${ }^{\circledR}$, nDawaplus ${ }^{\circledR}$, ICON Maxx ${ }^{\circledR}$. WHO Pesticide Evaluation Scheme; 2008.

6. WHO. Prequalification vector control. Geneva: World Health Organization; 2020.

7. Gnanguenon V, Azondekon R, Oke-Agbo F, Sovi A, Ossè R, Padonou G, et al. Evidence of man-vector contact in torn long-lasting insecticidetreated nets. BMC Public Health. 2013;13:751.

8. WHO. Guidelines for laboratory and field testing of long-lasting insecticidal mosquito nets. Geneva: World Health Organization; 2013.

9. WHO. Report of the nineteenth WHOPES Working Group Meeting, 8-11, February 2016, Review of: Veeralin LN, Vectomax GR, Bactivec SC. WHO Pesticide Evaluation Scheme; 2016.

10. Corbel V, Chabi J, Dabire RK, Etang J, Nwane P, Pigeon O, et al. Field efficacy of a new mosaic long-lasting mosquito net (PermaNet 3.0) against pyrethroid-resistant malaria vectors: a multi-centre study in Western and Central Africa. Malar J. 2010;27:113.

11. Pennetier C, Bouraima A, Chandre F, Piameu M, Etang J, Rossignol M, et al. Efficacy of Olyset ${ }^{\circledR}$ Plus, a new long lasting insecticidal net incorporating permethrin and piperonyl-butoxide against multi-resistant malaria vectors. PLOS ONE. 2013;8:e75134.

12. Toe KH, Müller P, Badolo A, Traore A, Sagnon N, Dabire RK, et al. Do bed nets including piperonyl butoxide offer additional protection against populations of Anopheles gambiae s.l. that are highly resistant to pyrethroids? An experimental hut evaluation in Burkina Faso. Med Vet Entomol. 2018;32:7-16.

13. N'Guessan R, Asidi A, Boko P, Odjo A, Akogbeto M, Pigeon O, et al. An experimental hut evaluation of PermaNet ${ }^{\circledR}$ 3.0, a deltamethrin-piperonyl butoxide combination net, against pyrethroid-resistant Anopheles gambiae and Culex quinquefasciatus mosquitoes in southern Benin. Trans $R$ Soc Trop Med Hyg. 2010;104:758-65.

14. WHO. Report of the twentieth WHOPES Working Group Meeting, 20-24, March 2017, Review of: Interceptor G2 LN, DawaPlus 3.0 LN, DawaPlus 4.0 LN, Sumilarv 2 MR, Chlorfenaoyr 240 SC. WHO Pesticide Evaluation Scheme; 2017.
15. WHO. Conditions for deployment of mosquito nets treated with a pyrethroid and piperonyl butoxide. Global Malaria Programme, Geneva:World Health Organization; 2017.

16. Sahu SS, Dash S, Sonia T, Gunasekaran K. Synergist piperonyl butoxide enhances the efficacy of deltamethrin in deltamethrin resistant Anopheles culicifacies sensu lato in malaria endemic districts of Odisha state, India. Indian J Med Res. 2019;149:554-7.

17. Sahu SS, Thankachy S, Dash S, Gunasekaran K, Kumar A. Intensity of pyrethroid resistance in Anopheles culicifacies s.l. (Diptera: Culicidae) in Odisha State, India. Pathog Glob Health. 2020;114:205-11.

18. Gunasekaran K, Sahu SS, Vijayakumar T, Subramanian S, Rahi M, Jambulingam P. Evaluation of MAGNet, a long-lasting insecticidal mosquito net against Anopheles fluviatilis in experimental huts in India. Malar J. 2019;18:59.

19. Gunasekaran K, Sahu SS, Vijayakumar T, Subramanian S, Rahi M, Jambulingam P. Evaluation of DawaPlus 3.0 and DawaPlus 4.0, deltamethrin-PBO combination nets against pyrethroid-resistant Anopheles culicifacies in experimental huts in India. Malar J. 2020;19:43.

20. WHO. Conditions for use of long-lasting insecticidal nets treated with a pyrethroid and piperonyl butoxide. Global Malaria Programme. Geneva: World Health Organization; 2015.

21. Gleave K, Lissenden N, Richardson M, Choi L, Ranson H. Piperonyl butoxide $(\mathrm{PBO})$ combined with pyrethroids in insecticide-treated nets to prevent malaria in Africa. Cochrane Database Syst Rev. 2018;11:CD012776.

22. Bingham G, Strode C, Tran L, Khoa PT, Jamet HP. Can piperonyl butoxide enhance the efficacy of pyrethroids against pyrethroid-resistant Aedes aegypti? Trop Med Int Health. 2011;16:492-500.

23. Oumbouke WA, Rowland M, Koffi AA, Alou LPA, Camara S, N'Guessan R. Evaluation of an alpha-cypermethrin + PBO mixture long-lasting insecticidal net VEERALIN ${ }^{\circledR}$ LN against pyrethroid resistant Anopheles gambiae s.s.: an experimental hut trial in M'bé, central Côte d'Ivoire. Parasit Vectors. 2019;12:544.

24. Moiroux N, Chandre F, Hougard JM, Corbel V, Pennetier C. Remote effect of insecticide-treated nets and the personal protection against malaria mosquito bites. PLOS ONE. 2017;12:e0170732.

25. Protopopoff N, Mosha JF, Lukole E, Charlwood JD, Wright A, Mwalimu $C D$, et al. Effectiveness of a long-lasting piperonyl butoxide-treated insecticidal net and indoor residual spray interventions, separately and together, against malaria transmitted by pyrethroid-resistant mosquitoes: a cluster, randomized controlled, two-by-two factorial design trial. Lancet. 2018;391:1577-88.

\section{Publisher's Note}

Springer Nature remains neutral with regard to jurisdictional claims in published maps and institutional affiliations.
Ready to submit your research? Choose BMC and benefit from:

- fast, convenient online submission

- thorough peer review by experienced researchers in your field

- rapid publication on acceptance

- support for research data, including large and complex data types

- gold Open Access which fosters wider collaboration and increased citations

- maximum visibility for your research: over $100 \mathrm{M}$ website views per year

At BMC, research is always in progress.

Learn more biomedcentral.com/submissions 